Int. J. Electrochem. Sci., 16 (2021) Article ID: 210456

International Journal of

ELECTROCHEMICAL

SCIENCE

$\underline{\text { www.electrochemsci.org }}$

\title{
Synthesis of Rose-Like Sheet Zinc Phosphate by the Induction- Calcination Method and Its Application as a Corrosion Inhibitor in Coatings
}

\author{
Yabo Chen ${ }^{1, £}$, Jihu Wang ${ }^{1, £}$, Shaoguo Wen ${ }^{1, *}$, Jijia Zhang ${ }^{2}$, Xiangyi Yu ${ }^{3}$, Yan Mao ${ }^{3}$ \\ ${ }^{1,2}$ College of Chemistry and Chemical Engineering, Shanghai University of Engineering Science, \\ Shanghai, 201620, China \\ ${ }^{3}$ Solid Waste and Chemicals Management Center of Ministry of Ecology and Environment, Beijing, \\ 100101, China \\ ${ }^{\mathfrak{E}}$ These two authors contributed equally to this work and should be considered co-first authors. \\ *E-mail: sgwen1@ sues.edu.cn
}

doi: $10.20964 / 2021.04 .63$

Received: 18 December 2020 / Accepted: 23 February 2021 / Published: 28 February 2021

\begin{abstract}
Rose-like sheet zinc phosphate (SZP) was prepared by the induction-calcination method using emulsified paraffin emulsion. The structure of SZP prepared under different conditions was characterized by X-ray photoelectron spectroscopy, X-ray diffractometer, Fourier transform infrared spectroscopy, and Scanning electron microscope. It was added as an anti-corrosive filler to waterborne epoxy-modified acrylic resin. The failure behavior of the coating film was studied by salt spray test and electrochemical workstation. Compared with pure resin, the best neutral salt spray resistance time increased from 24 hours to 336 hours, about 14 times. Besides, the contact angle of the film was measured with a contact angle meter. The results show that SZP can increase the contact angle of the film, improve the water-resistance of the epoxy-modified acrylic resin coating, and prolong the diffusion path of the corrosive medium to the substrate. Therefore, the rose-like sheet zinc phosphate enhances the barrier performance of the coating and can be used as an excellent corrosion inhibitor.
\end{abstract}

Keywords: Epoxy-modified acrylic resin, Sheet zinc phosphate, Nanomaterials, Coatings, Anticorrosion

\section{$\underline{\text { FULL TEXT }}$}

(C) 2021 The Authors. Published by ESG (www.electrochemsci.org). This article is an open access article distributed under the terms and conditions of the Creative Commons Attribution license (http://creativecommons.org/licenses/by/4.0/). 